\title{
Heat-induced illness
}

\author{
Christina Simpson MSc, Alan Abelsohn MD
}

\section{Extreme heat causes a substantial number of deaths}

The European heat wave of 2003 resulted in more than 70000 deaths, $28.9 \%$ of which were attributed to heatstroke, hyperthermia or dehydration. ${ }^{1}$ Extreme heat recently contributed to 106 deaths in Montréal, Quebec, and 156 deaths in Vancouver, British Columbia. ${ }^{2}$ Extreme heat events are expected to become more common in Canada as the climate continues to change. Increased health risks from extreme heat can be induced by high temperature and humidity, and can be exacerbated by other factors such as air pollution or a person's underlying physiology. ${ }^{3}$ Urban areas are more affected because of the "urban heat-island effect."

\section{It is important to differentiate heat exhaustion from heatstroke}

Heat exhaustion is the most common heat illness. Although the patient may have hot skin and be flushed and sweating, his or her core temperature is below $40^{\circ} \mathrm{C}$. In heatstroke, the core temperature is above $40^{\circ} \mathrm{C}$, the patient's mental status may change, and he or she may become incoherent or unconscious. In classic heatstroke, the skin is usually hot, red and dry; in exertional heatstroke, there is profuse sweating after high-intensity physical activity.

\section{Many people are vulnerable to heat}

Case-control studies have identified people with chronic physical conditions (cardiovascular, pulmonary, renal and neurologic disease, diabetes and obesity) and those with mental illness as vulnerable to extreme heat because of their underlying physiology. ${ }^{4}$ Older people, children and people who are very physically active in the heat are also at higher risk for heat-related illness. ${ }^{5}$ Common drugs such as antipsychotic agents, antidepressant medications (e.g., selective serotonin reuptake inhibitors, lithium), diuretic agents, antihistamines, anticholinergic agents and anti-Parkinson agents can increase risk by interfering with thermoregulatory mechanisms. ${ }^{6}$

\section{Heatstroke is a medical emergency}

Heatstroke can progress rapidly to multiorgan dysfunction and death. Treatment must be immediate and consists of rapid cooling (evaporative cooling for classic heatstroke; ice-water baths for young adults and people with exertional heat stroke). ${ }^{7}$ Careful attention should be paid to the patient's hydration and electrolyte balance to restore blood pressure and tissue perfusion. ${ }^{3}$

\section{References}

1. Hémon D, Jougla E. The heat wave in France in August 2003. Rev Epidemiol Sante Publique 2004; 52:3-5.

2. Kosatsky T. Hot day deaths, summer 2009: what happened and how to prevent a recurrence. $B M C J$ 2010;52:261.

3. Luber G, McGeehin M. Climate change and extreme heat events. Am J Prev Med 2008;35:429-35.

4. Bouchama A, Dehbi M, Mohamed G, et al. Prognostic factors in heat wave related death: a metaanalysis. Arch Intern Med 2007;167:2170-6.

5. Hajat S, O'Connor M, Kosatsky T. Health effects of hot weather: from awareness of risk factors to effec-

\section{Resources}

- E-learning module on the health impacts of extreme heat (www.extremeheat.ca).

- Climate change and health (www.healthcanada.gc.ca/cc).
Death from heat exposure is preventable

Observational studies support increasing fluid intake and reducing activity levels during hot weather, and cool or air-conditioned environments for people most vulnerable to heat. ${ }^{5}$ Various Canadian communities have implemented heat alert and response systems that include issuing public health messages, opening cooling centres and extending hours for public swimming pools. tive health protection. Lancet 2010;375:856-63.

6. Cuddy M.L. The effects of drugs on thermoregulation. AACN Clin Issues 2004;15:238-53.

7. Bouchama A, Dehbi M, Chaves-Carballo E. Cooling and hemodynamic management in heatstroke: practical recommendations. Crit Care 2007;11: R54-64.

Competing interests: None declared.

This article has been peer reviewed.

Affiliations: From the Healthy Environments and Consumer Safety Branch (Simpson, Abelsohn), Health Canada, Ottawa, Ont.; and the Department of Family and Community Medicine (Abelsohn), University of Toronto, Toronto, Ont.

Correspondence to: Christina Simpson, christina .simpson@hc-sc.gc.ca

CMAJ 2012. DOI:10.1503/cmaj.120492 